\title{
The role of slope on the overland flow production
}

\author{
R. Morbidelli ${ }^{1}$, C. Corradini ${ }^{1}$, C. Saltalippi ${ }^{1}$, A. Flammini ${ }^{1}$ \\ \& R. S. Govindaraju ${ }^{2}$ \\ ${ }^{I}$ Department of Civil and Environmental Engineering, \\ Perugia University, Italy \\ ${ }^{2}$ School of Civil Engineering, Purdue University, USA
}

\begin{abstract}
An experimental investigation of the surface runoff and deep flow produced by artificial rainfalls on sloping soil surfaces is presented. Starting from large values of initial moisture content, the relation between these two quantities and slope is examined through 15 experiments carried out using a soil with a sloping surface of $1^{\circ}, 5^{\circ}$ and $10^{\circ}$. A laboratory box $152 \mathrm{~cm}$ long, $122 \mathrm{~cm}$ wide and $78 \mathrm{~cm}$ deep was used. The overland flow was measured in the middle of the flow path, while the deep flow at the slope outlet. The average rainfall rate, $r$, was generally chosen to be less than the soil saturated hydraulic conductivity, $\mathrm{K}_{\mathrm{s}}$. It was found that for a given rainfall rate greater slopes determine larger surface runoff and smaller deep flow. The observed results are in agreement with those obtained earlier by Essig et al.; however the effect of slope variation appears to be more pronounced because of the different range used for $\mathrm{r} / \mathrm{K}_{\mathrm{s}}$ and the different soil selected. Current theories and experimental investigations performed by other authors do not explain appropriately the results described in this paper. Lastly, an overall comparison of the results showed here with those presented by Essig et al., obtained by measurements of overland flow at the slope outlet, suggests that the influence of the downstream wall on the amount of surface and deep flow is not significant.

Keywords: hill slope hydrology, overland flow, infiltration process, laboratory experiments.
\end{abstract}




\section{Introduction}

The transformation of rainfall in overland flow at a hill slope scale is strictly linked with the process of infiltration, which has been widely investigated but generally at a local scale for horizontal surfaces. More specifically, for local infiltration the extended Philip equation (Chow et al. [2]) and the Green-Ampt model extended by Mein and Larson [3] are the classical approaches typically selected in the context of rainfall-runoff simulations for isolated storm events, while in the case of complex rainfall patterns with successive infiltration-soil water redistribution cycles an appropriate model was proposed by Corradini et al. [4]. Extensions of infiltration modelling from the local to the field scale were developed by Smith and Goodrich [5] and by Govindaraju et al. [6] for vertically homogeneous soils, while a formulation for two-layered soils with a more permeable upper layer was developed by Corradini et al. [7]. However, both overland flow and deep flow in most real basins are generated by rainfall over hill slopes with different gradients. Therefore, the aforementioned models should be extended in order to represent the infiltration and the overland and deep flows production as functions of the slope angle.

This issue has been examined, for example, by Poesen [8] through an experimental investigation, by Philip [9] who developed a theoretical formulation for infiltration and by Essig et al. [1] through a comparison of numerical and experimental results. Poesen [8] set up laboratory experiments using artificial rainfalls and found that, for light rainfalls, infiltration and overland flow were not affected by variations in the gradient of the land surface, while for heavy rainfall rates determining the formation of a crust layer the infiltration rate increased with slope angle. Philip [9] proposed an extension of the classical infiltration theory earlier developed for horizontal land surfaces (Philip $[10,11]$ ) considering a long planar sloping surface with an infinite extent of a homogeneous isotropic soil characterized by a uniform initial moisture content. By applying the Richards equation for the flow both normal and parallel to the slope a complete analytical solution in the form of a series solution and two simplified relations for different time intervals were obtained. Philip showed that the gravitational effect decreases by a factor $\cos \gamma$, where $\gamma$ is the angle of the sloping surface with the horizontal, which implies a reduction of about $13 \%$ from $\gamma=0$ to $\gamma=30^{\circ}$. The difference between the Poesen experimental results and the Philip theoretical results appears to be rather limited. Essig et al. [1] performed laboratory experiments in a planar slope with a $\gamma$ variable between $1^{\circ}$ and $15^{\circ}$ and found that increased slope has a positive influence on overland flow and this influence increases relatively with decreasing rainfall rate. Furthermore, the observed behaviour of deep and overland flows for varying slopes could not be approximately explained by current theories. Thus, different mathematical models were set up to support the observed data. An overall analysis of the aforementioned results indicates that there are considerable differences to be justified.

This problem could be ascribed to the differences among the initial and boundary conditions used in the analytical approach by Philip [9] and those 
involved in the experiments performed by Poesen [8] and Essig et al. [1]. On these bases, the first objective of this paper is to investigate the influence of the downstream wall of the soil box used by Essig et al. [1] on the amount of overland flow observed for different values of $\gamma$ representative of most real situations. In fact, this wall represented the major critical element in the earlier experiments because, as suggested by the authors, the flow pattern might be distorted sufficiently and the overland flow measured at the box outlet strongly influenced. We analyse here new experiments performed by minimizing the wall effect on the results and starting approximately from the condition of high water content of the soil layer. The second objective is to extend the last experimental analysis of the flows as functions of $\gamma$ to situations with rainfall rate, $r$, less than the saturated hydraulic conductivity, $\mathrm{K}_{\mathrm{s}}$.

\section{Experimental system}

The laboratory slope system used is shown in fig. 1. A soil box $152 \mathrm{~cm}$ long, 122 $\mathrm{cm}$ wide, and $78 \mathrm{~cm}$ deep was used. The box slope is adjustable from $1^{\circ}$ to a maximum of approximately $15^{\circ}$. The sides are impermeable and transparent.

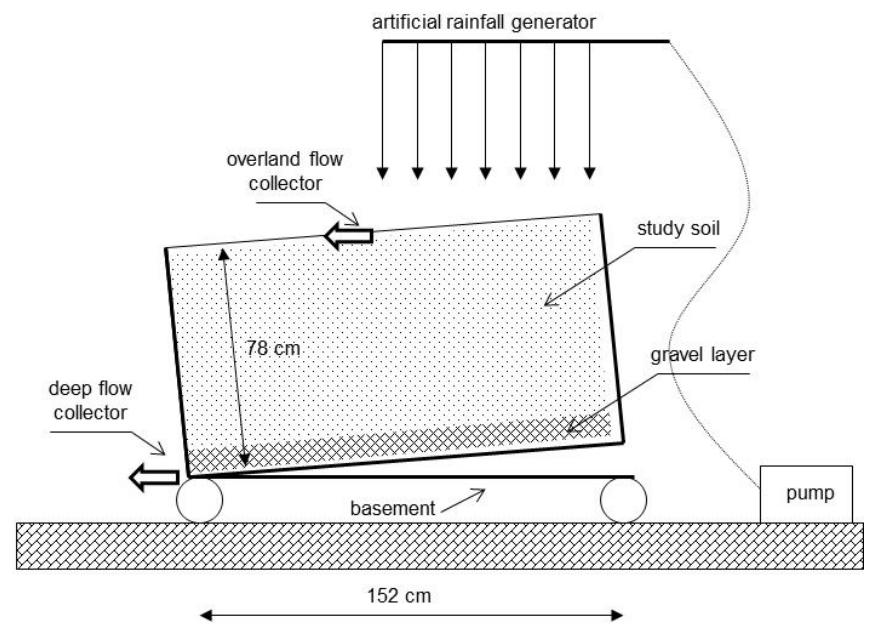

Figure 1: The laboratory experimental apparatus.

A $7 \mathrm{~cm}$ gravel layer separated by a textile mesh below the soil (see fig. 2) speeds the drainage of the percolated water.

The porous medium for the experiments (hereinafter called the "study soil") was taken from a natural soil then divided into different diameter classes. Lastly, by recombining fixed quantities of material of each class (13\% of clay, $40 \%$ of silt, $47 \%$ of sand) a homogeneous loam soil, according to the USDA soil classification, was obtained. 
Surface runoff and deep flow were measured using two calibrated tippingbucket sensors placed approximately in the middle of the flow path and at the end of the slope, respectively.

Artificial rainfall, approximately uniform through the soil surface, was generated through sprinklers of water under pressure supplied by a pump. Rain rate was chosen by an appropriate selection of the sprinkler and adjustment of the water pressure. The outflows from the sprinklers were calibrated in advance and tested before the beginning of experimental runs. A sheet metal pan, placed on the soil surface, caught the rainfall generated by the sprinkler and the outflow was measured. The rainfall spatial distribution was checked by a grid of pans.

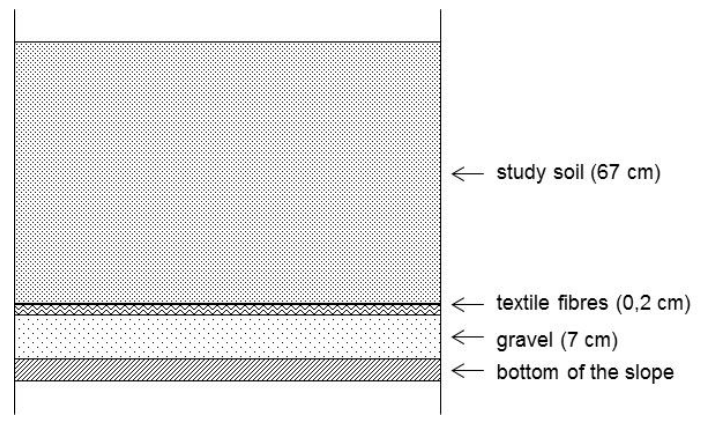

Figure 2: $\quad$ Cross section of the slope system.

At the beginning of each experiment the laboratory slope system was inclined at a fixed slope $\gamma$. A total of 15 experiments were performed and they were divided into three groups corresponding to different slopes. For a given slope, the group of experimental runs was performed with five different rainfall rates ranging from 16.48 to $39.13 \mathrm{~mm} \mathrm{~h}^{-1}$. Each experimental run lasted more than $20 \mathrm{~h}$, while rainfall was applied for $6 \mathrm{~h}$. Before the beginning of each experiment, rainfall was applied in order to have soil saturation at any depth. Furthermore, in the period between two successive experiments the surface water content was kept sufficiently high in order to avoid the formation of cracks. In spite of the calibration of the system producing artificial rainfall, the average rainfall rate in a given experiment was generally found to be a little different from the expected reference value.

\section{Results}

The main experimental results are synthesized in table 1 . The steady overland flow and deep flow, both reduced to the specific contributing area, are given for different slopes and different observed average rainfall rates. Because rainfall occurs only on the part of the soil surface contributing to the observed surface runoff (see also fig. 1), all the quantities are reduced to this portion of the surface. 
We note that, as earlier specified, for a given water pressure the average rainfall rate exhibited some appreciable differences with slope, but in any case these were irrelevant for the accuracy of the results in light of the investigation of the slope effect on the overland flow production. Furthermore, from table 1, for the case with nearly horizontal soil surface $\left(\gamma=1^{\circ}\right)$, the soil saturated hydraulic conductivity should be approximately $32 \mathrm{~mm} \mathrm{~h}^{-1}$ because this was the maximum deep flow observed for the minimum rainfall rate generating overland flow.

Table 1: $\quad$ Surface and deep steady flows generated by different water pressures. The observed values of the average rainfall rate are also given.

\begin{tabular}{lccccc}
\hline & \multicolumn{5}{c}{ Water pressure (bar) } \\
\cline { 2 - 6 } & $\mathbf{0 . 5}$ & $\mathbf{0 . 7}$ & $\mathbf{0 . 8}$ & $\mathbf{0 . 9}$ & $\mathbf{1 . 0}$ \\
\hline Slope $1^{\circ}$ & & & & & \\
Steady surface flow $\left(\mathrm{mm} \mathrm{h}^{-1}\right)$ & 0 & 0 & 0 & 0 & 6.50 \\
Steady deep flow $\left(\mathrm{mm} \mathrm{h}^{-1}\right)$ & 18.43 & 24.33 & 29.63 & 30.97 & 32.63 \\
Average rainfall rate $\left(\mathrm{mm} \mathrm{h}^{-1}\right)$ & 18.43 & 24.33 & 29.63 & 30.97 & 39.13 \\
Slope 5 & & & & & \\
Steady surface flow $\left(\mathrm{mm} \mathrm{h}^{-1}\right)$ & 8.08 & 11.85 & 10.75 & 11.96 & 15.34 \\
Steady deep flow $\left(\mathrm{mm} \mathrm{h}^{-1}\right)$ & 10.35 & 13.23 & 16.90 & 18.29 & 15.71 \\
Average rainfall rate $\left(\mathrm{mm} \mathrm{h}^{-1}\right)$ & 18.43 & 25.08 & 27.65 & 30.25 & 31.05 \\
& & & & & \\
Slope 10 & & & & & \\
Steady surface flow $\left(\mathrm{mm} \mathrm{h}^{-1}\right)$ & 7.77 & 13.88 & 17.87 & 20.68 & 19.47 \\
Steady deep flow $\left(\mathrm{mm} \mathrm{h}^{-1}\right)$ & 8.71 & 7.98 & 7.90 & 7.71 & 7.93 \\
Average rainfall rate $\left(\mathrm{mm} \mathrm{h}^{-1}\right)$ & 16.48 & 21.86 & 25.77 & 28.39 & 27.40 \\
\hline
\end{tabular}

It can be deduced from our results that the experiments for $\gamma=1^{\circ}$ were performed starting from a soil moisture content less than the saturation value at least in the upper soil layer and surface saturation was not reached for water pressure up to 0.9 bar, as suggested by the absence of surface runoff which became appreciable only for average rainfall rate larger than the saturated hydraulic conductivity. All the experiments with $\gamma=5^{\circ}$ and $\gamma=10^{\circ}$ were realized using $r<\mathrm{K}_{\mathrm{s}}$ and under these conditions saturation of the whole soil profile was not obtained, as suggested by the values of deep flow of considerably less than $32 \mathrm{~mm} \mathrm{~h}^{-1}$. However, surface runoff was generated in each experiment even with average rainfall rate of $\sim 18 \mathrm{~mm} \mathrm{~h}^{-1}$ for $\gamma=5^{\circ}$ and $\sim 16 \mathrm{~mm} \mathrm{~h}^{-1}$ for $\gamma=10^{\circ}$. Furthermore, as can be seen in table 1, the quantity of deep flow decreases considerably when the slope increases, while the surface runoff experiences an opposite behavior.

This result agrees with those obtained by Essig et al. [1] for different soils under rainfall rates much greater than the soil saturated hydraulic conductivity. In particular, their conclusion that the dependence of overland flow on $\gamma$ became relatively more important with decreasing rainfall rate is confirmed considering that the slope influence has a greater role also for rainfall rates less than the 
saturated hydraulic conductivity. Table 2, which provides sample experimental results referred to Soils 1 and 2 used by Essig et al. [1] and the soil selected here, supports the aforementioned analysis. Specifically, in each soil greater slopes determine larger surface runoff and smaller deep flow, but in the experiments referred to the soil selected here, with $\mathrm{r} / \mathrm{K}_{\mathrm{s}} \approx 1$, the steady surface flow normalized by the average rainfall rate increases from 16.61 to $71.06 \%$ for $\gamma$ varying from $1^{\circ}$ to $10^{\circ}$. On the other hand, in Soil 1 and Soil 2 used by Essig et al. [1], with $\mathrm{r} / \mathrm{K}_{\mathrm{s}} \approx 3$, the positive influence of the slope on the same quantity is rather smaller and limited to $\sim 20 \%$ and $\sim 6 \%$, respectively.

As to the behavior of surface flow and deep flow in each experiment, figs. 3 5 show their evolution as a function of time for three representative experiments

Table 2: $\quad$ Surface and deep steady flows for different slope angles observed in the Study Soil and in two soils used earlier by Essig et al. [1]. In parentheses the flows are normalized by the average rainfall rate.

\begin{tabular}{cccc}
\hline $\begin{array}{c}\text { Slope } \\
{\left[{ }^{\circ}\right.}\end{array}$ & $\begin{array}{c}\text { Average rainfall rate } \\
{[\mathbf{m m} / \mathbf{h}]}\end{array}$ & $\begin{array}{c}\text { Steady surface flow } \\
{[\mathbf{m m} / \mathbf{h}-\mathbf{( \% )}]}\end{array}$ & $\begin{array}{c}\text { Steady deep flow } \\
{[\mathbf{m m} / \mathbf{h}-\mathbf{( \% )}]}\end{array}$ \\
\hline Study Soil & & & \\
1 & 39.13 & $6.50-(16.61)$ & $32.63-(83.39)$ \\
5 & 31.05 & $15.34-(49.40)$ & $15.71-(50.60)$ \\
10 & 27.40 & $19.47-(71.06)$ & $7.93-(28.94)$ \\
Soil 1 (Essig et al., [1]) & & & \\
1 & 9.86 & $6.73-(68.26)$ & $3.13-(31.74)$ \\
5 & 9.74 & $7.69-(78.95)$ & $2.05-(21.05)$ \\
10 & 10.07 & $8.83-(87.69)$ & $1.24-(12.31)$ \\
Soil 2 (Essig et al., [1]) & & & \\
1 & 9.81 & $6.73-(68.60)$ & $3.08-(31.40)$ \\
5 & 9.77 & $7.04-(72.06)$ & $2.73-(27.94)$ \\
10 & 9.91 & $7.43-(74.97)$ & $2.48-(25.03)$ \\
\hline
\end{tabular}

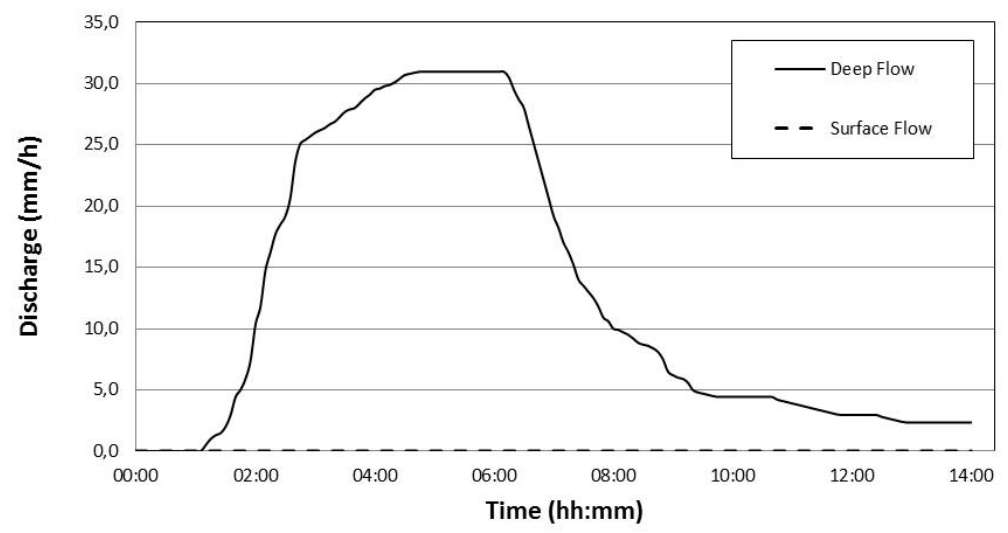

Figure 3: $\quad$ Surface and deep flow hydrographs observed for a slope angle of $1^{\circ}$ and produced by a rainfall rate of $30.97 \mathrm{~mm} \mathrm{~h}^{-1}$ with a duration of $6 \mathrm{~h}$. 


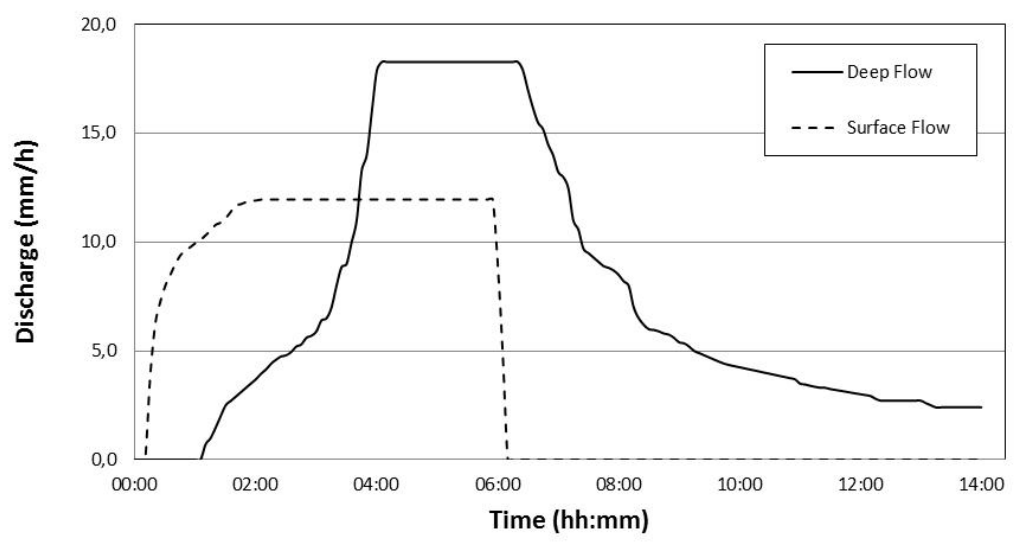

Figure 4: $\quad$ Surface and deep flow hydrographs observed for a slope angle of $5^{\circ}$ and produced by a rainfall rate of $30.25 \mathrm{~mm} \mathrm{~h}^{-1}$ with a duration of $6 \mathrm{~h}$.

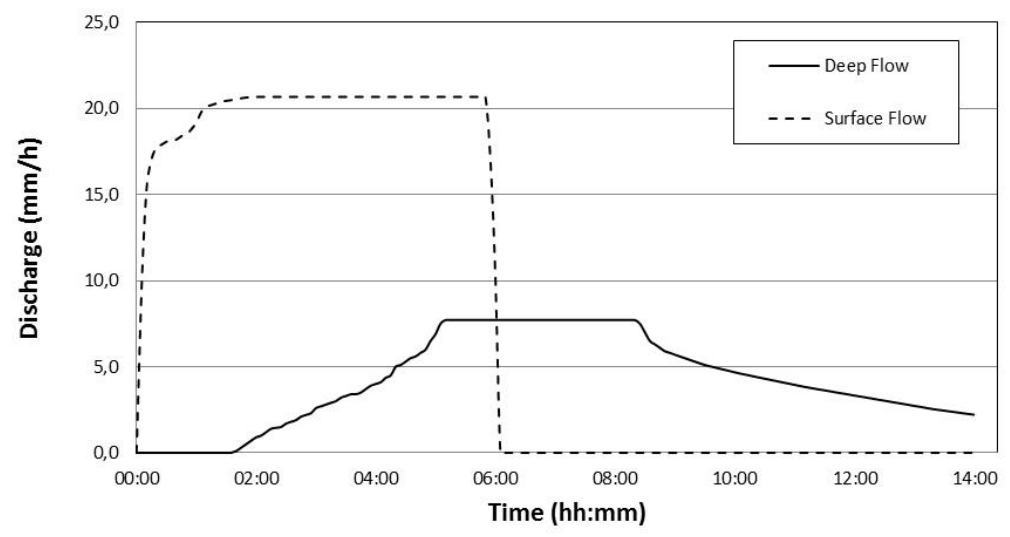

Figure 5: $\quad$ Surface and deep flow hydrographs observed for a slope angle of $10^{\circ}$ and produced by a rainfall rate of $28.39 \mathrm{~mm} \mathrm{~h}^{-1}$ with a duration of $6 \mathrm{~h}$.

carried out using the same water pressure ( 0.9 bar), leading to rather similar rainfall rates, for each sloping surface stage. For overland flow with $\gamma=5^{\circ}$ and $10^{\circ}$, each hydrograph exhibits a steady state approached within $2 \mathrm{~h}$ after time for ponding with the duration up to a few minutes after the rainfall was turned off, while no tail is present in agreement with the measurements by Essig et al. [1] who found this characteristic only for fine-textured soils. The shape of the deep flow curves appears to be consistent with that of surface flow. 


\section{Conclusions}

On the basis of our results three main elements can be considered of major interest:

a) by comparing these results with the data published by Essig et al. [1] and examining the different experimental approaches for the rainfall spatial distribution and the location of the sensor for surface runoff measurements, it appears that the downstream box wall does not affect significantly the existing relation between the amount of surface-deep flow and the soil surface slope;

b) the field of great interest of the above relation is extended to rainfall rates less than the soil saturated hydraulic conductivity;

c) the variation of surface-deep flow with slope is considerable and does not appear to be adequately described by the current theoretical and experimental approaches.

\section{Acknowledgment}

This research was mainly financed by the Italian Ministry of Education, University and Research (PRIN 2010/2011).

\section{References}

[1] Essig, E.T., Corradini C., Morbidelli, R. and Govindaraju, R.S., Infiltration and deep flow over sloping surfaces: Comparison of numerical and experimental results. Journal of Hydrology, 374, pp. 30-42, 2009.

[2] Chow, V.T., Maidment, D. R. and Mays, L. W., Applied Hydrology, McGraw-Hill: New York, 1988.

[3] Mein, R.G. and Larson, C.L., Modeling infiltration during a steady rain. Water Resources Research, 9(2), pp. 384-394, 1973.

[4] Corradini, C., Melone, F. and Smith, R.E., A unified model for infiltration and redistribution during complex rainfall patterns. Journal of Hydrology, 192, pp. 104-124, 1997.

[5] Smith, R.E. and Goodrich, D.C., Model for rainfall excess patterns on randomly heterogeneous areas. Journal of Hydrologic Engineering, 5(4), pp. 355-362, 2000.

[6] Govindaraju, R.S., Morbidelli, R. and Corradini, C., Areal infiltration modelling over soils with spatially correlated hydraulic conductivities. Journal of Hydrologic Engineering, 6(2), pp. 150-158, 2001.

[7] Corradini, C., Flammini, A., Morbidelli, R. and Govindaraju, R.S., A conceptual model for infiltration in two-layered soils with a more permeable upper layer: From local to field scale. Journal of Hydrology, 410, pp. 62-72, 2011. 
[8] Poesen, J., The Influence of Slope Angle on Infiltration Rate and Hortonian Overland Flow Volume. Zeitschrift fur Geomorphologie N.F., 49, pp. 117131, 1984.

[9] Philip, J.R., Hillslope Infiltration: Planar Slopes. Water Resources Research, 27(1), pp. 109-117, 1991.

[10] Philip, J.R., The theory of infiltration, 1, The infiltration equation and its solution. Soil Science, 83, pp. 345-357, 1957.

[11] Philip, J.R., Theory of infiltration. Advances in Hydrosciences, 5, pp. 215216, 1969. 